\title{
Genome Sequence and Experimental Infection of Calves with Bovine Gammaherpesvirus 4 (BoHV-4)
}

\section{Fernando Bauermann}

Oklahoma State University Medical Library: Oklahoma State University Center for Health Sciences

\section{Shollie Falkenberg}

USDA-ARS NADC: USDA-ARS National Animal Disease Center

Mathias Martins

Cornell University College of Veterinary Medicine

\section{Rohana Dassanayake}

USDA-ARS NADC: USDA-ARS National Animal Disease Center

John Neill

USDA-ARS NADC: USDA-ARS National Animal Disease Center

Julia Ridpath

USDA-ARS NADC: USDA-ARS National Animal Disease Center

\section{Simone Silveira}

USDA-ARS NADC: USDA-ARS National Animal Disease Center

\section{Mitchell Palmer}

USDA-ARS NADC: USDA-ARS National Animal Disease Center

\section{Alaine Buysse}

SDSU: South Dakota State University

\section{Anna Mohr}

SDSU: South Dakota State University

\section{Eduardo Flores}

UFSM: Universidade Federal de Santa Maria

Diego G. Diel ( $\nabla$ dgdiel@cornell.edu )

Cornell University College of Veterinary Medicine https://orcid.org/0000-0003-3237-8940

\section{Research Article}

Keywords: BoHV-4, gammaherpesvirus, herpesvirus, calves, pathogenesis

Posted Date: January 20th, 2022

DOI: https://doi.org/10.21203/rs.3.rs-1264393/v1 
License: (c) (i) This work is licensed under a Creative Commons Attribution 4.0 International License. Read Full License 


\section{Abstract}

Bovine gammaherpesvirus 4 (BoHV-4) is ubiquitous in cattle worldwide and it has been detected in animals exhibiting broad clinical presentations. The virus has been detected in the United States since the 70's, however, its clinical relevance remains unknown. Here we determined the complete genome sequence of two contemporary BoHV-4 isolates and assessed clinical, virological and pathological outcomes upon intranasal (IN) inoculation in calves. A slight and transient increase in body temperature was observed in BoHV-4-inoculated calves. Additionally, transient viremia and virus shedding in nasal secretions were observed in all inoculated calves. BoHV-4 DNA was detected by nested-PCR in the tonsil and regional lymph nodes ( $\mathrm{LNs}$ ) of calves euthanized on day 5 post-inoculation (pi) and in the lungs of calves euthanized on day 10 pi. Calves euthanized on day 35 pi harbored BoHV-4 DNA in the respiratory tract (turbinates, trachea, lungs), regional lymphoid tissues and trigeminal ganglia. Interestingly, in situ hybridization (ISH) revealed the presence of BoHV-4 DNA in nerve bundles surrounding the trigeminal ganglia and retropharyngeal lymph nodes (day $35 \mathrm{pi}$ ). No histological changes were observed in the respiratory tract (turbinate, trachea and lung), lymphoid tissues (tonsil, LNs, thymus and spleen), or central nervous tissues (olfactory bulb and trigeminal ganglia) sampled throughout the animal studies (days 5, 10 and $35 \mathrm{pi}$ ). This study contributes to the understanding of the infection dynamics and tissue distribution of BoHV-4 following IN infection in calves. These results suggest that the two contemporary isolates used in our study present low virulence and pathogenicity to calves upon intranasal inoculation.

\section{Introduction}

Bovine gammaherpesvirus 4 (BoHV-4) is widespread in cattle worldwide and it has been isolated from healthy animals and from animals presenting a variety of clinical signs, including respiratory or reproductive disorders [1-5]. The role of BoHV-4 in overt disease, however, remains unknown. The virus has a broad geographic distribution and has been detected in cattle in Europe, America, Asia and Africa [6-10]. Originally, BoHV-4 has been classified in the subfamily Betaherpesvirinae, genus Cytomegalovirus based on the formation of high-density inclusion bodies and induction of giant cells in-vitro. However, genome structure analysis [11] and the presence of the thymidine kinase gene [12] led to its reclassification in the Rhadinovirus genus, subfamily Gammaherpesvirinae [13]. The BoHV-4 genome consists of a double-stranded DNA molecule with 108,873 bp and an overall G+C content of $41.4 \%$ containing at least 79 open reading frames, with 17 of them being unique to BoHV-4 [14].

The virus was first isolated in 1963 in Hungary from calves exhibiting keratoconjunctivitis and respiratory distress [6]. In 1971, BoHV-4 was reported in the United States following isolation from tissues of a bovine with respiratory disease [8]. Based on genomic restriction patterns, two BoHV-4 groups were initially recognized and named after the prototype virus strains [15]. The European group was named Movar 33/63-like viruses whereas the American group was referred to as DN599-like virus [15]. Viruses of both groups are not restricted geographically [11] and given their genetic differences, the European and American groups have been suggested to belong to genotype 1 and 2, respectively [16]. The biological relevance of the genomic differences observed in the two BoHV-4 genotypes, however, remains unknown. 
While members of the family Bovidae are thought to be the natural hosts of BoHV-4, it is hypothesized that the virus originally circulated among African bison and may have "spilled over" to cattle [17]. In cattle, BoHV-4 has been isolated from healthy animals as well as from animals presenting a variety of clinical conditions including abortion, metritis, vulvovaginitis, mastitis, pneumonia, keratoconjunctivitis and dermatitis $[1,6-8,18-22]$. The role of the virus in these clinical presentations, however, is largely unknown. The tropism of BoHV-4 for cells of the monocyte/macrophage lineage during lytic and latent infection [23] may explain - at least in part - the frequent isolation of the virus from diverse tissues and inflammatory conditions. Experimental inoculations of BoHV-4 in cattle through different inoculation routes demonstrated that the virus primarily replicates in epithelial cells in the nasal mucosa, followed by viremia associated with peripheral blood mononuclear cells (PBMCs) [20, 24-26]. It has been suggested that BoHV-4 may establish latent infection in lymphoid and neuronal tissues [20, 25-27].

In the present study, we determined the complete genome sequences of two contemporary BoHV-4 isolates and assessed the clinical, virological and pathological outcomes upon intranasal inoculation in calves.

\section{Material And Methods}

\section{Viruses and cells}

The isolates SD16-38 and SD16-49 were obtained in 2016 at Animal Disease Research and Diagnostic Laboratory at South Dakota State University (ADRDL-SDSU) using bovine turbinate (BT) cells (ATCC; CRL1390). BoHV-4 SD16-49 was isolated from a cow with a reproductive disorder; isolate SD16-38 was recovered from lung tissue from a calf with respiratory disease. The isolate SD16-49 was further amplified and titrated using Madin-Darby Bovine kidney cells (MDBK, ATCC, CCL-22). Whereas bovine turbinate cells (BT) were used for amplification and titrations of isolate SD16-38. Cells were tested free of non-cytopathic bovine viral diarrhea virus (BVDV). Cells were cultured at $37^{\circ} \mathrm{C}$ with $5 \% \mathrm{CO}_{2}$ in minimum essential medium (MEM) (Corning, Corning, NY) supplemented with $10 \%$ fetal bovine serum (FBS; VWR, Radnor, PA), penicillin $(100 \mathrm{IU} / \mathrm{ml})$, streptomycin $(100 \mu \mathrm{g} / \mathrm{ml})$, and gentamicin $(50 \mu \mathrm{g} / \mathrm{ml})$ (Corning, Corning, NY).

\section{Whole genome sequence and characterization}

Supernatants of BoHV-4-inoculated cell monolayers (SD16-38 and SD16-49) were subjected to high throughput sequencing using the Illumina MiSeq sequencing platform. DNA libraries were prepared using the Nextera XT DNA library kit (Illumina) following the manufacturer's protocol. The DNA library was quantitated using Qubit dsDNA assay kit (Life Technologies). Library DNA (4 nM) was loaded into a MiSeq Nano Flow Cell (300 cycles, Illumina) and sequenced with the Illumina MiSeq sequencing platform (Illumina). Three individual rounds of sequencing were performed and results combined to generate a consensus sequence for both BoHV-4 isolates. The BoHV-4 genome sequences were assembled with Ray [28], and the repeats were resolved using Celera [29] and Cap3 [30] software's. Open reading frames 
(ORFs) for BoHV-4 isolates SD16-38 and SD16-49 were inferred and annotated using Geneious Prime software based on the genomic sequences of BoHV-4 strains 66-p-377 and FMV09 (GenBank accession numbers AF318573 and KC999113.1).

\section{Animal study design}

Two separate experiments were conducted to investigate the pathogenesis of contemporary BoHV-4 isolates. In experiment 1 four $(n=4)$ five month-old calves, negative for BoHV-4 neutralizing antibodies were used. After transport, animals were acclimated for 14 days and inoculated intranasally (IN) with BoHV-4 isolate SD16-49 (titer $10^{6.3} \mathrm{TCID}_{50} / \mathrm{mL}-5 \mathrm{ml}$ in each nostril). Animals were monitored daily for respiratory and systemic clinical signs. Rectal temperature was checked and recorded daily. Nasal swabs and blood samples were collected daily up to day 14 post-inoculation (pi). All procedures of animal handling and experimentation were conducted under veterinary supervision and according to recommendations by the Brazilian Committee of Animal Experimentation (approved by Institutional Ethics Committee UFSM - CEUA/UFSM protocol number 034/2014).

In experiment 2 eighteen 3-week-old colostrum-deprived Holstein bull calves negative for BoHV-4 neutralizing antibodies were allocated in three groups [31]. Following seven days of acclimation, 10 calves were inoculated with a suspension of BoHV-4 isolate SD16-38 $\left(10^{6.0} \mathrm{TCID}_{50} / \mathrm{mL}\right)$ via IN instilation ( $5 \mathrm{ml}$ in each nostril). Four calves were mock-inoculated with MEM ( $5 \mathrm{ml}$ in each nostril) and kept as controls and the last four calves served as non-inoculated contact animals that were comingled with the inoculated animals starting at day 3 pi to evaluate potential virus transmission. Nasal swabs and blood samples were collected on days $-1,0,3,5,7$ and $10 \mathrm{pi}$. Two control calves and four inoculated calves were euthanized on days $5 \mathrm{pi}$ and $10 \mathrm{pi}$. The four contact calves were euthanized on day $10 \mathrm{pi}$. The two remaining inoculated calves were euthanized on day 35 pi. Additional serum sampling for neutralizing antibody titration was performed on day $35 \mathrm{pi}$ for the two inoculated calves. During the course of the study, animals were monitored daily and scored for clinical signs using Calf Health Scorer system developed at the University of Wisconsin School of Veterinary. Body temperature was constantly monitored using ruminal probes as previously described [31]. Euthanasia was performed with a pentobarbital sodium injection (Fatal Plus, Vortech Pharmaceutical Ltd., Dearborn, MI). The animals were handled in accordance with the Animal Welfare Act Amendments (7 U.S. Code §2131 to §2156) and all procedures were approved by the Institutional Animal Care and Use Committee of the National Animal Disease Center (ARS-2016-572).

\section{Sample collection and processing}

Blood samples were collected by jugular venipuncture with Vacuette tubes containing clot activator (for serum), heparin (for PBMCs) or ethylenediaminetetraacetic (for complete blood cells count; CBC) (Greiner Bio-One, Monroe, NC). Serum samples were aliquoted and stored at $-20{ }^{\circ} \mathrm{C}$ until tested. Blood samples collected with heparin were centrifuged at $1200 \mathrm{Xg}$ for $10 \mathrm{~min}$ and the buffy coat was transferred to a cryotube and stored at $-80^{\circ} \mathrm{C}$ until use. Tissues collected at necropsy from animals in experiment 2 
included: nasal turbinate, thymus, tonsil, lung, spleen, olfactory bulb, trigeminal ganglia and lymph nodes (mandibular, retropharyngeal, tracheobronchial). Tissues were fixed by immersion in $10 \%$ neutral buffered formalin for RNAscope testing and placed in bags and frozen DNA extraction and PCR testing. Tissues were stored at $-80^{\circ} \mathrm{C}$ until use.

\section{Viral DNA extraction and nested-PCR}

Total DNA was extracted from serum, buffy coats and nasal swab samples using QIAamp ${ }^{\circledR}$ DNA (Qiagen) according to the manufacturer's instructions. In addition, total DNA was extracted from tissues collected in experiment 2, as follow: approximately $1 \mathrm{~g}$ of tissue was minced with sterile scalpel blade and mixed with $9 \mathrm{ml}$ of MEM (1:10 w/v). Samples were homogenized with Stomacher and centrifuged $1200 \mathrm{Xg}$ for 10 min. DNA was extracted from tissue homogenates using QIAamp ${ }^{\circledR}$ DNA (Qiagen) according to the manufacturer's instructions. BoHV-4 DNA was detected using a previously described nPCR [24] with minor modifications. Briefly, nPCR targeting the BoHV-4 thymidine kinase region employed the following primers: 5'-GTTGGGCGTCCTGTATGGTAGC-3' (primer 1), 5'-ATGTATGCCCAAAACTTATAATATGACCAG-3' (primer 2), 5'-TTGATAGTGCGTTGTTGGGATGTGG-3' (primer 3), and 5'-CACTGCCCG GTGGGAAATAGCA-3' (primer 4). Primers 1 and 2 flanked a 567-bp fragment and the internal primers (primers 3 and 4) amplified a 260-bp product. Both PCR amplifications were performed with the same protocol using $50 \mu \mathrm{l}$ reactions containing $25 \mu \mathrm{l}$ of the Q5 hot start high-fidelity 2X master mix (New England Biolabs), $2.5 \mu \mathrm{l}$ of each primer (final concentration of $0.5 \mu \mathrm{M}$ ), $19 \mu \mathrm{l}$ nuclease-free water (Thermo-Fisher Scientific), and $1 \mu \mathrm{l}$

of purified nucleic acid as template. The PCR conditions consisted of five initial amplification cycles at 94 ${ }^{\circ} \mathrm{C}$ for $45 \mathrm{~s}, 56^{\circ} \mathrm{C}$ for $1 \mathrm{~min}, 72{ }^{\circ} \mathrm{C}$ for $1.5 \mathrm{~min}$. Subsequently, an additional 25 cycles of $94{ }^{\circ} \mathrm{C}$ for $45 \mathrm{~s}, 51$ ${ }^{\circ} \mathrm{C}$ for $1 \mathrm{~min}$, and $72{ }^{\circ} \mathrm{C}$ for $1.5 \mathrm{~min}$ were performed followed by $72{ }^{\circ} \mathrm{C}$ for $5 \mathrm{~min}$. PCR amplicons were analyzed by $1 \%$ agarose gel electrophoresis.

\section{Virus isolation and quantification}

Virus isolation in cell cultures was attempted from nasal swabs in experiment 1 (MDBK cells) and from serum, buffy coats and nasal swabs in experiment 2 (BT cells). Nasal swabs were placed in microtubes with $500 \mu \mathrm{l}$ of MEM, vortexed for at least $30 \mathrm{~s}$ and $150 \mu \mathrm{l}$ were inoculated in each well. For buffy coats and serum, $150 \mu \mathrm{l}$ were inoculated in the wells and adsorption was performed for $1 \mathrm{~h}$. Cells were washed with MEM twice and $500 \mu \mathrm{l}$ of replacement media supplemented with $10 \%$ FBS were added to each well. Three passages were performed in $70-80 \%$ confluent cell monolayers. Plates were incubated at $37^{\circ} \mathrm{C}$ with $5 \% \mathrm{CO}_{2}$ and monitored daily for 6 days. Positive samples were quantified by limiting dilution and the titers calculated according to Reed and Muench method [32].

\section{Virus neutralizing assays}

Virus neutralization (VN) assays were performed with serum samples from experiment 2 (collected at day $35 \mathrm{pi}$ ). Briefly, serum dilutions from 1:2 to $1: 512$ were incubated with $200 \mathrm{TCID}_{50}$ of the homologous virus (isolate SD16-38) during $90 \mathrm{~min}$ at $37^{\circ} \mathrm{C}$, followed by addition of a suspension of BT cells and incubation 
for 7 days at $37^{\circ} \mathrm{C}$ in $5 \% \mathrm{CO}_{2}$. Tests were read under light microscope for the presence of cytopathic effect. Neutralizing antibody titers were determined as the reciprocal of the highest serum dilution capable of completely inhibiting BoHV-4 replication.

\section{RNAscope $^{\circledR}$ in situ hybridization}

RNAscope ${ }^{\circledR}$ in situ hybridization assay was used to investigate the presence of viral nucleic acid in tissues collected during experiment 2 from the animals necropsied on day 35 pi. Tissue sections were fixed by immersion in 10\% neutral buffered formalin for 24 - $36 \mathrm{~h}$, transferred to $70 \%$ ethyl alcohol until processed by standard paraffin-embedment techniques, cut in $5 \mu \mathrm{m}$ sections for in situ viral labeling. Sequence from BoHV-4 isolate SD16-38 was used to design gene-specific oligonucleotide target probes per the manufacture's recommendation. Labeling of viral nucleic acid using proprietary probes designed specifically to the BoHV-4 identification (Advanced Cell Diagnostics, Hayward, CA, USA) was performed according to manufacturer's instructions for RNAscope ${ }^{\circledR}$ 2.0. Positive and negative control probes were used for verification of specificity of the assay. The positive control probe consisted of a proprietary probe for Bos taurus ubiquitin C (UBC; Cat \# 464851), while the negative control probe targeted dapB of Bacillus subtilis (Cat \# 312038).

Upon completion of the RNAscope ${ }^{\circledR} 2.0$ assay and drying for approximately $15 \mathrm{~min}$, slides were cover slipped using mounting media (EcoMount, Biocare Medical, Concord, CA, USA). Slides were scanned at 40X magnification and digitized using the Aperio ScanScope XT workstation (Aperio Technology, Inc., Vista, CA, USA). Digitized images were visualized using image analysis software (HALO ${ }^{\mathrm{Tm}}$, Indica Labs, Inc., Corrales, NM) to describe BoHV-4 labeling patterns and compare to histological observations.

\section{Results}

\section{Sequencing and genome characterization}

Whole genome sequencing for both isolates was conducted after amplification in cell culture. Low passage viral stocks (p. 4) were used for sequencing. Genome sequencing of isolate SD16-38 (GenBank accession number MN551083) followed by blastn (National Library of Medicine) of the long unique region (LUR) $108.669 \mathrm{nt}$ long revealed over 99.8\% similarity with isolate 66-p-377 (AF318573), a member of the BoHV-4 genotype 1. The coding region of conserved genes typically employed for BoHV-4 classification, including the DNA polymerase (DNA pol) and thymidine kinase (TK) genes, respectively displayed $99.7 \%$ and $100 \%$ nucleotide (nt) identity between SD16-38 and 66-p-377. The glycoproteins gB, $\mathrm{gH}$, and $\mathrm{gM}$ were $100 \%$ identical between BoHV-4 SD16-38 and 66-p-377, whereas $99.3 \%$ similar for the $\mathrm{gL}$. The SD16-49 genome (MN551084) shares the highest similarity with another member of the BoHV-4 genotype 1 (isolate FMV09 - KC999113.1), over $99.9 \%$ similarity for the LUR which is $108.478 \mathrm{nt}$ in length. The DNA pol, TK, gB, gH and gM coding regions are 100\% identical between SD16-49 and FMV09, whereas $99.5 \%$ similarity for the gL coding region. The similarity between SD16-38 and SD16-49 for the 
coding regions of $\mathrm{gB}, \mathrm{gH}, \mathrm{gL}$ and $\mathrm{gM}$ were respectively, $95.5 \%, 96.1 \%, 98.6 \%$ and $99.5 \%$. Whereas coding regions for the DNA pol and TK were $98.8 \%$ and $99.6 \%$, respectively.

\section{Clinical and virological findings following intranasal BoHV-4 inoculation}

No overt respiratory signs were observed in 5 month-old calves inoculated with BoHV-4 isolate SD16-49 in experiment 1. A slight increase in body temperature was recorded in these calves at days 4 and 5 pi (Fig. 1A). Infectious BoHV-4 was isolated from nasal secretions from all calves on days 1-2 pi, from three calves up until day $3 \mathrm{pi}$ and from one calf up to day 5 pi. Peak virus titers $\left(10^{4} \mathrm{TCID}_{50} / \mathrm{mL}\right)$ were observed on day 3 pi (Fig. 1B). BoHV-4 DNA was detected in buffy coats of all four inoculated calves. Animals \#67 and 68 presented buffy coat associated viremia for 3-4 days, whereas animals \#72 and 66 presented viremia up to days 12 and 14, respectively (Table 1). Together, these results demonstrated that BoHV-4 isolate SD16-49 replicated in the upper respiratory tract of calves after IN inoculation and produced a short-term viremia in inoculated animals. Virus replication in the nasal mucosa was not followed by production of nasal and/or respiratory signs; mild systemic signs (hyperthermia) were observed only transiently.

In experiment 2, no respiratory signs were observed in the 10-colostrum deprived 5-week old calves following IN inoculation with BoHV-4 isolate SD16-38. A slight transient increase in body temperature was observed at days 8 and 9 pi (Fig. 2A). In addition, inoculated animals presented a slight decrease in lymphocyte counts between days 5 and 7 pi (Fig. 2B). Both contact and control calves remained healthy throughout the observation period.

BoHV-4 DNA was detected by nPCR in nasal secretions from all BoHV-4-inoculated calves on day 3 pi and on the majority of nasal swabs collected on days 5 and 7 pi (Table 2). Attempts to isolate the virus from nasal swabs, serum and buffy coats were unsuccessful. Nonetheless, viral DNA was detected by nPCR in the blood (buffy coat, serum) of two contact calves (days 3 and $10 \mathrm{pi}$ ), suggesting virus transmission from the inoculated calves. Viral DNA was detected transiently in serum and buffy coats from most $(8 / 10)$ inoculated animals, between days 3 and $10 \mathrm{pi}$. These results indicated virus replication in the respiratory tract, transient viremia and short-term shedding of virus in nasal secretions.

The use of nPCR to detect BoHV-4 in tissues collected during necropsy indicated the presence of viral DNA in at least one tissue from all but one calf necropsied at $5 \mathrm{dpi}$ (\#4096) (Table 3). No viral DNA was detected in tissues from animals in the contact or control groups. Three animals euthanized on day 5 pi yielded positive results for viral DNA in tonsils and/or mandibular lymph node. Viral DNA was detected in the lungs, respiratory tract lymph nodes and/or spleen of calves euthanized at day $10 \mathrm{pi}$. Interestingly, most tissues were positive for both calves euthanized at day 35 pi. The use of RNAscope ${ }^{\circledR}$ in situ hybridization supported the NPCR findings showing the presence of viral DNA in both neuronal and lymphoid tissues of animals euthanized at day $35 \mathrm{pi}$ (Figs. 3A and 3B). Low levels of neutralizing antibodies were detected in sera of two calves at day $35 \mathrm{pi}$ (Table 2). 


\section{Discussion}

In the present study, we characterized the genomic and clinicopathological features of two contemporary BoHV-4 isolates following IN inoculation of these isolates in calves. The BoHV-4 isolate SD16-38 obtained from a case of respiratory disease showed higher similarity with the BoHV-4 genotype 166-p377 (AF318573) that was identified in 1960's [33]. The reproductive BoHV-4 isolate SD16-49 shared higher level of identity with isolate FMV09 (KC999113.1) that was recently (2009) isolated and sequenced from cattle with respiratory disease in Canada [7]. Detection of BoHV-4 genotype 1 in the US supports the notion that the so-called European BoHV-4 isolates are not geographically restricted to the cattle population in Europe. In fact, other members of the BoHV-4 genotype 1 have been already detected in the US and Canada [7, 34].

Results from recent animal studies suggest that the clinical consequences of BoHV-4 infection likely depend upon viral, host and environmental factors. A study with five BoHV-4 strains verified that only one strain produced respiratory disease in calves [26]. Similar to previous studies, no overt respiratory and/or systemic signs could be reproduced upon IN inoculation of calves [25, 35]. These findings seem to contrast with detection and isolation of the virus from cattle with respiratory disease [6-8]. Nonetheless, the role and contribution of BoHV-4 to respiratory disease in cattle is not clear. It is conceivable that, like other bovine respiratory infectious agents, BoHV-4 may act as a co-factor in in bovine respiratory disease syndrome. The ubiquitous nature of BoHV-4, its frequent isolation from healthy animals or from inflammatory conditions of the respiratory and reproductive tract combined with its ability to infect circulating monocytes, however, also suggest that detection of the virus in such a broad array of clinical presentations might incidental. Results from our study, in which calves were inoculated with high viral titers via the IN route and did not develop overt respiratory disease, suggest that BoHV-4 may not be a primary pathogen of respiratory disease in cattle.

Nonetheless, results here show that BoHV-4 efficiently replicated in the nasal mucosa and was shed transiently by inoculated animals. Additionally, viremia was observed in both experiments with variable duration. In experiment 1, viremia was detected transiently by PCR in two animals (days 2 -4/5), while the other two animals presented longer viremia (up to days 12-14). In experiment 2, viremia was detected in $8 / 10$ animals, between days 3 and 10 pi and was typically transient in all animals. A transient increase in body temperature was the only clinical change observed in both studies. In summary, IN inoculation of both viruses in seronegative calves was followed by transient replication, viremia and virus shedding in nasal secretions but did not result in overt respiratory disease. Interestingly, the isolate SD 16-49 apparently replicated with higher efficiency in the respiratory tract than isolate SD 16-38, though it has been isolated from reproductive disease.

Previous data have shown that environmental conditions may also influence BoHV-4 pathogenesis [20, 24]. While these two studies used the same methodology and viral strain to inoculate calves of roughly the same age, diverging results were observed regarding sites of BoHV-4 latency. The first study with 9 animals, found no evidence of the presence of BoHV-4 DNA in neurological tissues of any of the animals 
after day $28 \mathrm{pi}$ - period of time that could be considered sufficient to lead to viral latency in neurological tissues [20]. On the other hand, on a second study, in two animals kept for 62 days, BoHV-4 DNA was detected in neurological tissues by nPCR [24]. In the present study, both animals euthanized at $35 \mathrm{pi}$ presented viral DNA in the trigeminal ganglia and the retropharyngeal lymph node detected both by nPCR and RNAScope ISH. These results support that intranasal inoculation of BoHV-4 led to effective infection and establishment of latency in neuronal and lymphoid tissues, corroborating previous observations [26]. INterestingly, we observed an increasing number of positive tissues over the course of the study. BoHV-4 DNA was initially detected in the inoculation site and draining lymph nodes. Later, at day 35 , most of the tissues were positive for BoHV-4 DNA. These results suggest slow and progressive infection of tissues. Detection of virus and/or viral DNA in the buffy coats in both studies support dissemination of the virus associated with leukocytes. The transient detection of BoHV-4 DNA in lymphoid tissues of most inoculated animals of experiment 2 on days 5 and 10 pi suggest that these tissues might be targets for acute BoHV-4 replication whereas viral DNA detection of both lymphoid and neural sites (TGs) at day 35 pi suggest both tissues as sites of BoHV-4 latency. It is conceivable that, following IN inoculation and replication, the virus experiences a transient viremic spread that results, in a second moment, in infection of neural and lymphoid tissues and subsequent establishment of latency. Long-term viral persistence in lymphoid tissues has been demonstrated in initial studies of BoHV-4 pathogenesis in cattle [25, 35]. Likewise, sensory nerve ganglia (e.g. trigeminal ganglia) of naturally infected cattle have been shown to harbor latent BoHV-4 DNA [36]. Thus, current evidence support that lymphoid and neural tissues may serve as sites of BoHV-4 persistence/latency $[25,35]$. Nonetheless, the functional role of each of these sites in the BoHV-4 latency-reactivation cycle remains to be determined.

The route of BoHV-4 inoculation and the level of cell-associated viremia seem to play a role in the clinicpathologic outcome of infection. In a previous study, 7-day old calves inoculated with the European isolate Movar 33/63 BoHV-4 strain via the IN and intratracheal routes developed bronchitis and nasal discharge [20]. Virus shedding was detected in nasal and ocular discharges for 2 weeks post-infection and viremia was detected up to 12 days pi. The development of clinical signs and long-term shedding compared to the present study may reflect differences in virulence among strains, inoculation method and host factors as well. Intratracheal inoculation likely facilitates infection of epithelial lung cells, monocytes and macrophages, and may bypass part of the intrinsic and innate immune responses, leading to clinical signs and a higher level of cell-associated viremia. Bypassing the intrinsic and innate immune defenses has been described by intratesticular BoHV-4 inoculation of bulls, which led to conjunctivitis between days 14 and 18 pi and azoospermia between days 31 and 51 in one of the 5 inoculated animals [22]. Shedding through ocular secretions was also detected after day $19 \mathrm{pi}$.

In summary, the study described here provides evidence of subclinical BoHV-4 infection in calves and the ability of the virus to establish latency in neuronal and lymphoid cells following intranasal inoculation of calves. The increased frequency in isolation of BoHV-4 in cattle herds in the Midwest region of the US seem not to be caused by dissemination of strains with increased virulence and further investigations are required to fully understand the role of BoHV-4 in disease. It is conceivable that BoHV-4, similar to other agents involved in the bovine respiratory disease complex, may act as a co-factor in disease production. 
Additionally, given the lack of overt disease in our and other studies, the possibility that BoHV-4 may not be a primary disease-causing agent in cattle also has to be considered. Frequent isolation of the virus from healthy animals or from various inflammatory conditions may well be a result of the virus tropism, replication and latency in monocytes which function during those inflammatory conditions to clear damaged cells.

\section{Declarations}

\section{Funding}

The work was supported by ARS USDA Hatch Project project SD00H517-14.

\section{Conflict of Interest}

The authors declare that the research was conducted in the absence of any commercial or financial relationships that could be construed as a potential conflict of interest.

\section{Author Contributions}

Conceived the study: SFM, EFF, DGD. Tested experimental samples: FVB, SMF, MM, RPD, SS, MVP, AB, AM. Data analysis and result interpretation: FVB, SMF, MM, JDN, JFR, MVP, EFF, DGD. Manuscript writing: FVB, SMF, MM, EFF, DGD. All authors have reviewed and edited the manuscript.

\section{Acknowledgments}

The authors would like to thank the NADC animal facility staff and animal caretakers for the care and handling of the animals.

\section{Ethical approval}

All animals were handled in accordance with the Animal Welfare Act Amendments (7 U.S. Code $\S 2131$ to §2156) and all study procedures were reviewed and approved by the Institutional Animal Care and Use Committee at the National Animal Disease Center (ARS-2016-572) or by the Ethical Committee at UFSM (CEUA/UFSM protocol number 034/2014).

\section{Data Availability Statement}

The whole genome sequences generated in this study can be found in GenBank under accession numbers MN551083 and MN551084.

\section{References}

1. Wellenberg GJ, Van Der Poel WHM, Van Der Vorst TJK et al (2000) Bovine herpesvirus 4 in bovine clinical mastitis. Vet Rec. https://doi.org/10.1136/vr.147.8.222 
2. Czaplicki G, Thiry E (1998) An association exists between bovine herpesvirus-4 seropositivity and abortion in cows. Prev Vet Med 33:235-240. https://doi.org/10.1016/S0167-5877(97)00036-6

3. Chastant-Maillard S (2015) Impact of bovine herpesvirus 4 (BoHV-4) on reproduction. Transbound Emerg Dis 62:245-251. https://doi.org/10.1111/tbed.12155

4. Deim Z, Szeredi L, Tompó V, Egyed L (2006) Detection of bovine herpesvirus 4 in aborted bovine placentas. Microb Pathog 41:144-148. https://doi.org/10.1016/j.micpath.2006.03.006

5. Egyed L, Sassi G, Tibold J et al (2011) Symptomless intrauterine transmission of bovine herpesvirus 4 to bovine fetuses. Microb Pathog 50:322-325. https://doi.org/10.1016/j.micpath.2010.10.006

6. Bartha A, Juhasz M, Liebermann H (1966) Isolation of a bovine herpesvirus from calves with respiratory disease and keratoconjunctivitis. A preliminary report. Acta Vet Acad Sci Hung 16:357358

7. Gagnon CA, Traesel CK, Music N et al (2017) Whole Genome Sequencing of a Canadian Bovine Gammaherpesvirus 4 Strain and the Possible Link between the Viral Infection and Respiratory and Reproductive Clinical Manifestations in Dairy Cattle. Front Vet Sci 4:92. https://doi.org/10.3389/fvets.2017.00092

8. Mohanty SB, Hammond RC, Lillie MG (1971) A new bovine herpesvirus and its effect on experimentally infected calves. Brief report. Arch Gesamte Virusforsch 33:394-395

9. Rossiter PB, Gumm ID, Stagg DA et al (1989) Isolation of bovine herpesvirus-3 from African buffaloes (Syncerus caffer). Res Vet Sci 46:337-343

10. Moreno-Lopez J, Goltz M, Rehbinder C et al (1989) A bovine herpesvirus (BHV-4) as passenger virus in ethmoidal tumours in Indian cattle. Zentralbl Veterinarmed B 36:481-486

11. Ehlers B, Buhk HJ, Ludwig H (1985) Analysis of bovine cytomegalovirus genome structure: cloning and mapping of the monomeric polyrepetitive DNA unit, and comparison of European and American strains. J Gen Virol 66(Pt 1):55-68. https://doi.org/10.1099/0022-1317-66-1-55

12. Kit $\mathrm{S}$, Kit M, Ichimura $\mathrm{H}$ et al (1986) Induction of thymidine kinase activity by viruses with group $B$ DNA genomes: bovine cytomegalovirus (bovine herpesvirus 4). Virus Res 4:197-212

13. ICTV (2018) Virus Taxonomy: 2018 Release. Washington, DC

14. Zimmermann W, Broll H, Ehlers B et al (2001) Genome sequence of bovine herpesvirus 4, a bovine Rhadinovirus, and identification of an origin of DNA replication. J Virol 75:1186-1194. https://doi.org/10.1128/JVI.75.3.1186-1194.2001

15. Thiry E, Bublot M, Dubuisson J et al (1992) Molecular biology of bovine herpesvirus type 4. Vet Microbiol 33:79-92. https://doi.org/10.1016/0378-1135(92)90037-T

16. Verna AE, Manrique JM, Pérez SE et al (2012) Genomic analysis of bovine herpesvirus type 4 (BoHV4) from Argentina: High genetic variability and novel phylogenetic groups. Vet Microbiol 160:1-8. https://doi.org/10.1016/j.vetmic.2012.04.039

17. Dewals B, Thirion M, Markine-Goriaynoff $N$ et al (2006) Evolution of Bovine herpesvirus 4: Recombination and transmission between African buffalo and cattle. J Gen Virol 87:1509-1519. 
https://doi.org/10.1099/vir.0.81757-0

18. Wellenberg GJ, Bruschke CJM, Wisselink HJ et al (2002) Simultaneous intramammary and intranasal inoculation of lactating cows with bovine herpesvirus 4 induce subclinical mastitis. Vet Microbiol 86:115-129. https://doi.org/10.1016/S0378-1135(01)00496-5

19. Thiry E, Dubuisson J, Bublot M et al (1990) The biology of bovine herpesvirus-4 infection of cattle. Dtsch Tierarztl Wochenschr 97:72-77

20. Egyed L, Ballagi-Pordány A, Bartha A, Belák S (1996) Studies of in vivo distribution of bovine herpesvirus type 4 in the natural host. J Clin Microbiol 35:1091-1095

21. Egyed L (2000) Bovine herpesvirus type 4: a special herpesvirus (review article). Acta Vet Hung 48:501-513. https://doi.org/10.1556/004.48.2000.4.13

22. Dubuisson J, Thiry E, Bublot M et al (1989) Experimental infection of bulls with a genital isolate of bovine herpesvirus- 4 and reactivation of latent virus with dexamethasone. Vet Microbiol 21:97-114

23. Osorio FA, Rock DL, Reed DE (1985) Studies on the pathogenesis of a bovine cytomegalo-like virus in an experimental host. J Gen Virol 66:1941-1951. https://doi.org/10.1099/0022-1317-66-9-1941

24. Egyed L, Bartha A (1998) PCR studies on the potential sites for latency of BHV-4 in calves. Vet Res Commun 22:209-216

25. Osorio FA, Reed DE (1983) Experimental inoculation of cattle with bovine herpesvirus-4: evidence for a lymphoid-associated persistent infection. Am J Vet Res 44:975-980

26. Castrucci G, Frigeri F, Ferrari M et al (1987) Experimental infection of calves with strains of Bovid herpesvirus-4. https://doi.org/10.1016/0147-9571(87)90039-7. Comp Immunol Microbiol Infect Dis

27. Castrucci G, Frigeri F, Ferrari M et al (1987) Reactivation in calves of latent infection by Bovid herpesvirus-4. Microbiologica

28. Boisvert S, Raymond F, Godzaridis É et al (2012) Ray Meta: scalable de novo metagenome assembly and profiling. Genome Biol 13:R122. https://doi.org/10.1186/gb-2012-13-12-r122

29. Myers EW (2000) A Whole-Genome Assembly of Drosophila. Science (80-) 287:2196-2204. https://doi.org/10.1126/science.287.5461.2196

30. Huang X, Madan A (1999) CAP3: A DNA Sequence Assembly Program. Genome Res 9:868-877. https://doi.org/10.1101/gr.9.9.868

31. Falkenberg SM, Ridpath J, Vander Ley B et al (2014) Comparison of temperature fluctuations at multiple anatomical locations in cattle during exposure to bovine viral diarrhea virus. Livest Sci 164:159-167. https://doi.org/10.1016/j.livsci.2014.03.018

32. Finney DJ (1952) The Reed-Muench method. In: Statistical Method in Biological Assay

33. Storz J (1968) Comments on malignant catarrhal fever. J Am Vet Med Assoc 152:804-806

34. Areda D, Chigerwe M, Crossley B (2018) Bovine herpes virus type-4 infection among postpartum dairy cows in California: risk factors and phylogenetic analysis. Epidemiol Infect 146:904-912. https://doi.org/10.1017/S0950268818000791 
35. Delooz L, Czaplicki G, Houtain JY et al (2017) Laboratory Findings Suggesting an Association Between BoHV-4 and Bovine Abortions in Southern Belgium. Transbound Emerg Dis 64:1100-1109. https://doi.org/10.1111/tbed.12469

36. Homan EJ, Easterday BC (1981) Further studies of naturally occurring latent bovine herpesvirus infection. Am J Vet Res 42:1811-1813

\section{Tables}

Tables 1,2,3 are available in the Supplemental Files section.

\section{Figures}


Fig. 1

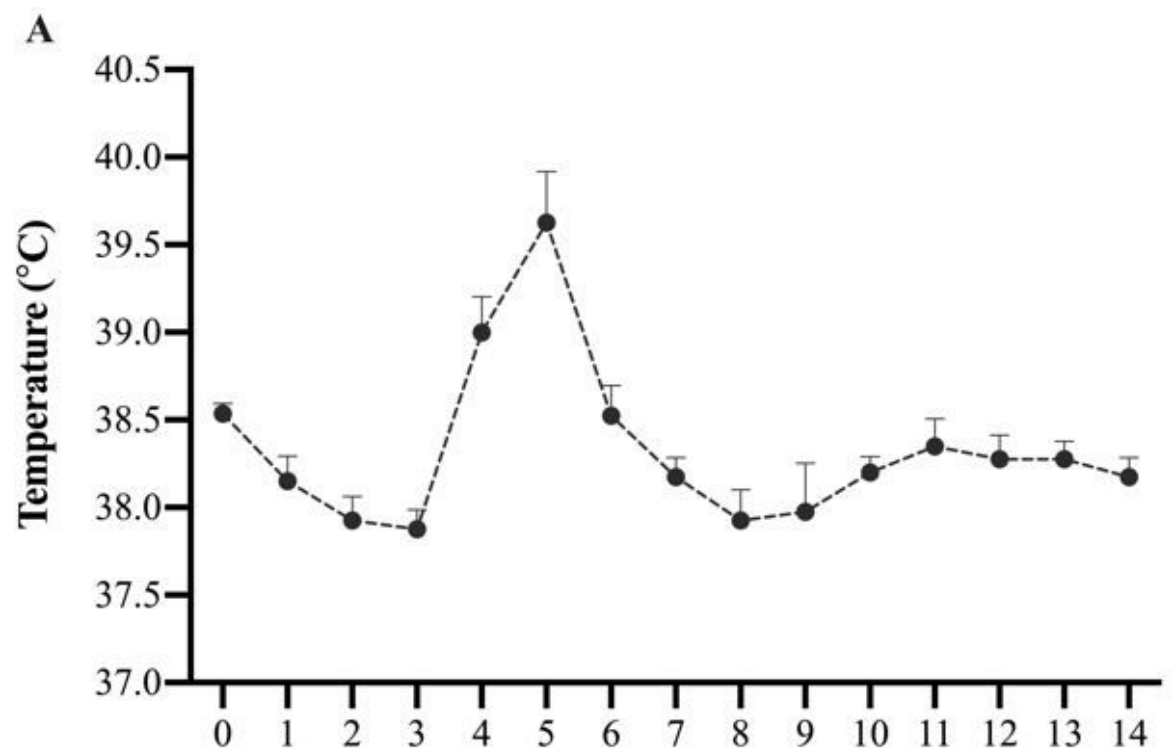

Days post-inoculation

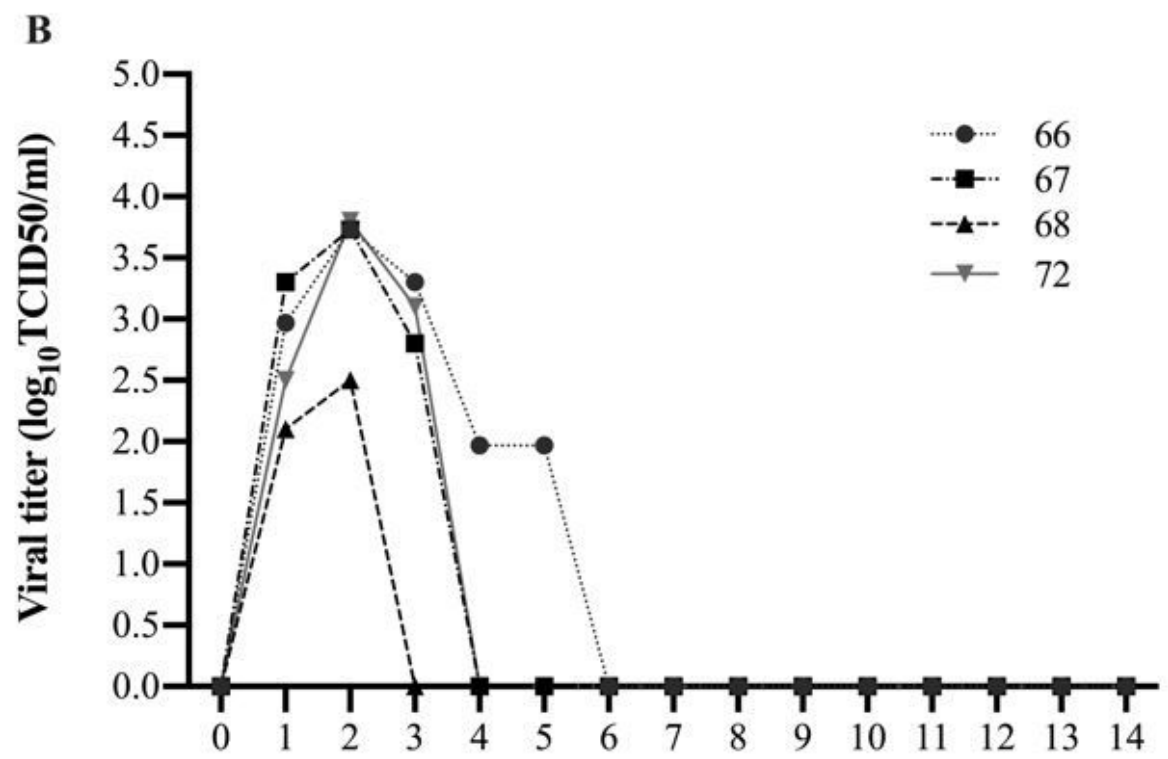

Days post-inoculation

Figure 1

Clinical and virological monitoring of calves from Experiment 1. Average rectal temperature in the days following virus inoculation (bars represent the standard error of the mean) (A) Virus titers in nasal secretions (B). 
Fig. 2

A
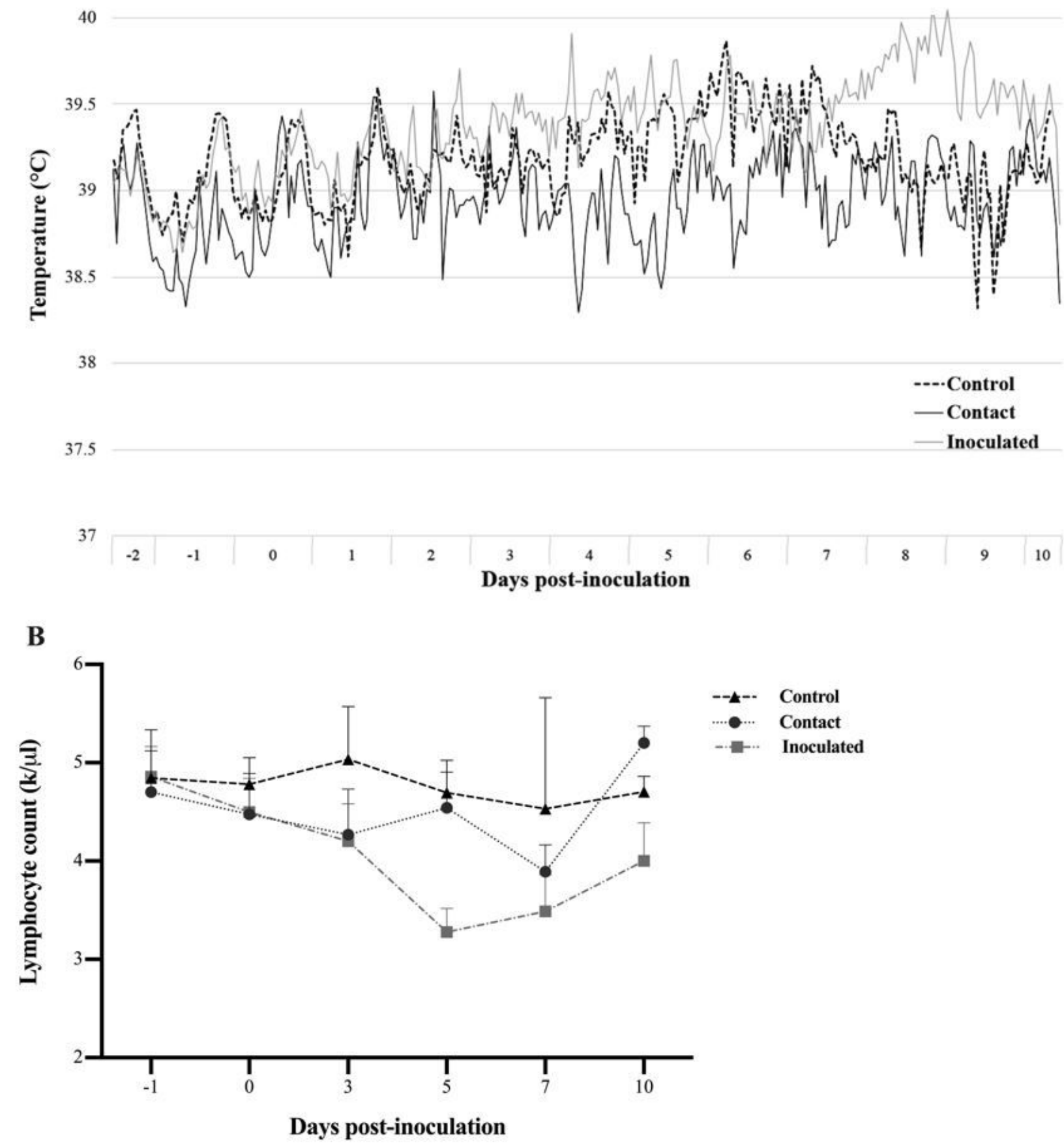

Figure 2

Clinical monitoring of calves from Experiment 2. Average of body temperature fluctuations recorded using ruminal probes in the days following virus inoculation (A) Average of lymphocyte counts for the three groups (B). Bars represent the standard error of the mean. 
Fig. 3

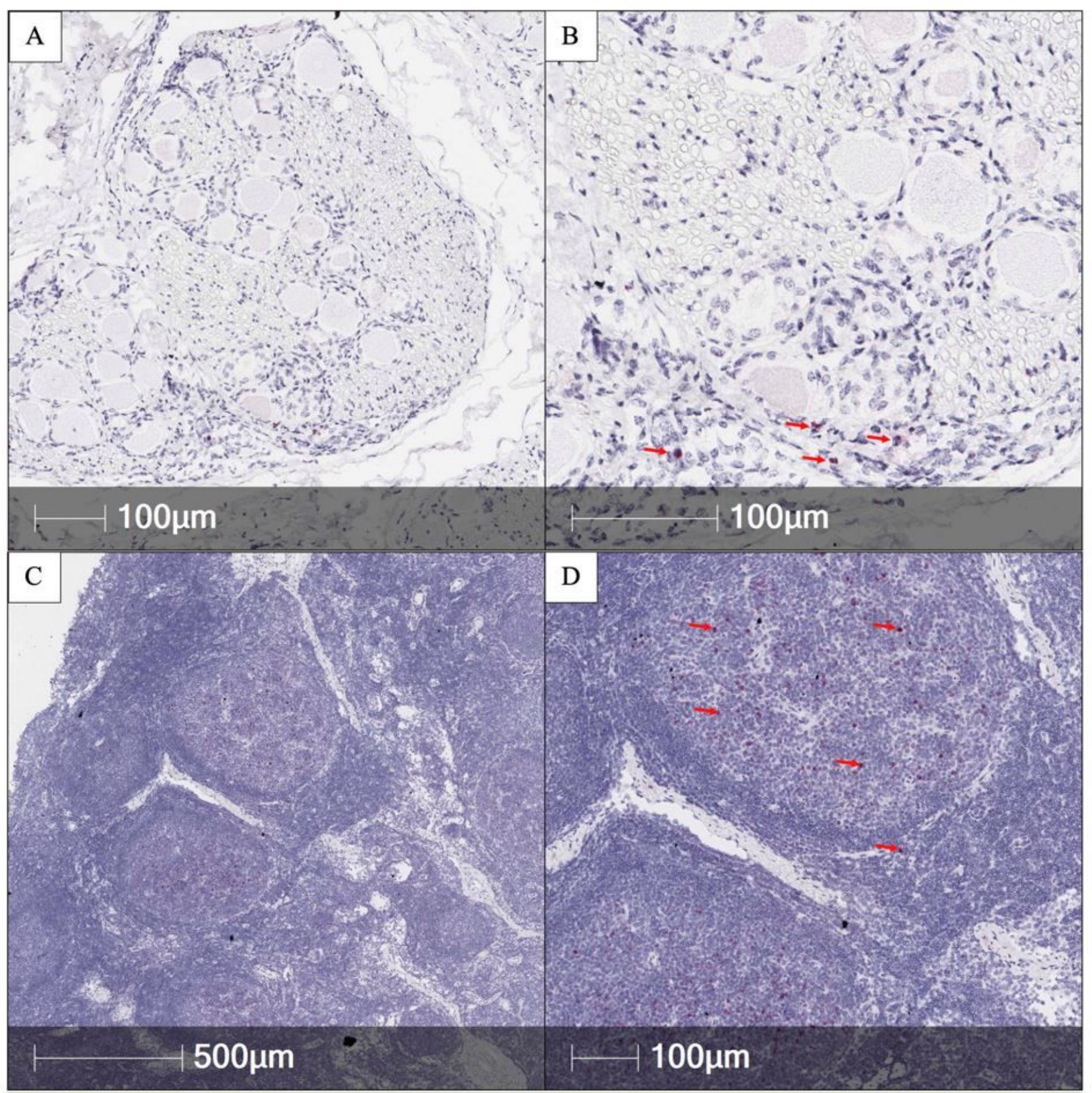

\section{Figure 3}

Detection of BoHV-4 DNA using RNAscope in nerve bundle from trigeminal ganglia (A and B) and retropharyngeal lymph node (C and $\mathrm{D})$. Red arrows indicate positive cells.

\section{Supplementary Files}


This is a list of supplementary files associated with this preprint. Click to download.

- Table1.jpg

- Table2.jpg

- Table3.jpg 